\title{
A Saúde nas Barras da Justiça: \\ Um Estudo do Posicionamento Recente do Supremo Tribunal FederaL ${ }^{(*)}$
}

\author{
HEALTH IN FRONT OF JUSTICE: A STUDY ABOUT THE RECENT \\ POSITION OF THE BRAZILIAN SUPREME COURT
}

Marco Aurélio Antas Torronteguy(**)

\section{INTRODUÇÃO}

O objetivo deste artigo é analisar recente decisão do Supremo Tribunal Federal (STF), notadamente os argumentos do voto do Relator, Ministro Gilmar Mendes, em que se discutiu o papel do Poder Judiciário em face das ações judiciais em que se pleiteia, individualmente, a realização do direito à saúde. A judicialização da saúde comporta uma tensão entre, de um lado, o papel do Poder Executivo para desenhar e pôr em marcha políticas públicas para acesso à saúde e, de outro lado, os deveres - e limites - do Judiciário para fazer valer o direito sempre que a sociedade e a cidadania se sentirem alijadas do exercício deste direito fundamental. A decisão em comento procura estabelecer balizas para o enfrentamento dessa tensão, esquadrinhando as possibilidades de atuação judicial em face da ausência ou do descumprimento de políticas de saúde pública. Antes de analisá-la mais detalhadamente, entretanto, é importante situar o debate em torno do reconhecimento do direito à saúde e da atuação do STF, com algumas referências a decisões anteriores deste mesmo Tribunal.

\footnotetext{
(*) Nota do editor: O voto completo do então Presidente do Supremo Tribunal Federal Gilmar Mendes está disponível em <http://redir.stf.jus.br/paginador/paginador.jsp?docTP=AC\&doclD=610255>. Assim, todos os trechos deste voto elencados no decorrer deste comentário podem ser consultados no endereço eletrônico mencionado.

$\left.{ }^{(*}\right)$ Doutor pela Faculdade de Direito da Universidade de São Paulo; mestre pela Universidade Federal de Santa Maria, pela UFSM (2006); pesquisador do CEPEDISA e do Núcleo de Pesquisa em Direito Sanitário da USP. E-mail: <marcoaurelio@usp.br>.

Recebido em 11.05.10. Aprovado em 25.05.10.
} 


\section{A SAÚDE CONQUISTA O DIREITO}

Em recente obra que sintetiza didaticamente o direito sanitário, Dallari e Serrano asseveram que apenas com a Constituição de 1988 a saúde foi reconhecida como um direito fundamental. Antes disso, a saúde, vista como prestação previdenciária, só estava ao alcance daqueles que contribuíam para a previdência social e seus dependentes, o que significava a exclusão de imensa quantidade de pessoas ${ }^{(1)}$.

Portanto, a inclusão do direito à saúde no rol dos direitos sociais, no art. 6o da Constituição Federal, significou importante avanço do direito brasileiro. Esse largo passo foi o resultado do intenso movimento social pela reforma sanitária, que desde os anos 1970 refletia sobre as iniquidades do acesso à saúde no Brasil. O art. 196, por sua vez, dá os contornos constitucionais para a realização deste direito fundamental:

A saúde é direito de todos e dever do Estado, garantido mediante políticas sociais e econômicas que visem a redução do risco de doença $e$ de outros agravos e ao acesso universal e igualitário às ações $e$ serviços para sua promoção, proteção e recuperação.(2)

Uma vez positivado constitucionalmente, o direito à saúde, estendido a todos, passou a ser reivindicado judicialmente como direito subjetivo público, contra o Estado. Neste ponto, é importante recordar que o direito, além de regulador, é também uma forma de representação da sociedade e, mais do que isso, ele é um instrumento de transformação social. Esse papel transformador é cumprido quando, por exemplo, o direito veicula políticas públicas, as quais existem para efetivar direitos fundamentais, como o direito à saúde.

O STF tem compartilhado essa percepção ao afirmar que o art. 196 constitucional "não pode converter-se em promessa constitucional inconsequente", de modo que "o sentido de fundamentalidade do direito à saúde (...) impõe ao Poder Público um dever de prestação positiva”(3). In casu, estava sendo analisada a possibilidade de obrigar o Município a fornecer medicamentos gratuitamente à pessoa de poucas posses. E o STF confirmou a fórmula constitucional do dever do Estado em sentido pleno, ou seja, em todas as esferas federativas, inclusive a municipal.

Neste sentido, a omissão do Poder Público, em face do dever de implementar políticas públicas, constitui-se "grave comportamento

(1) DALLARI, Sueli Gandolfi; NUNES JÚNIOR, V. S. Direito sanitário. São Paulo: Verbatim, 2010. p. $67,68,72,73$.

(2) BRASIL. Constituição Federal de 1988. Disponível em: <http://www.planalto.gov.br/ccivil_03/ Constituicao/Constitui\%C3\%A7ao.htm>. Acesso em: 1을 2010.

(3) BRASIL. Supremo Tribunal Federal. Agravo Regimental no Recurso Extraordinário n. 271.286-8RS. $2^{\text {a }}$ Turma. Min. Rel. Celso de Mello. Acórdão de 12 de setembro de 2000. Disponível em: <http:/ /redir.stf.jus.br/paginador/paginador.jsp?docTP=AC\&doclD=335538>. Acesso em: 1을 2010. 
inconstitucional"(4). A Constituição, no que concerne à saúde e aos direitos sociais de modo geral, estabelece um "imperativo de solidariedade social"(5) que corresponde ao direito público subjetivo(6) à saúde. A afirmação da saúde como direito fundamental individualmente exigível, inclusive judicialmente, contra o Poder Público, confirma a autonomia do direito sanitário e sua função social transformadora. Neste sentido, a Constituição estabeleceu o desafio da universalidade da saúde, pois se trata de um direito de todos.

E o STF confirmou esse entendimento, quando afirmou que o argumento da falta de recursos financeiros não se sobrepõe ao dever de garantir direitos correlatos à dignidade humana. Neste caso, discutia-se, em sede de Arguição de Descumprimento de Preceito Fundamental (ADPF), a possibilidade de o Judiciário interferir em políticas públicas. Embora o caso já estivesse prejudicado, o Min. Celso de Mello fez questão de firmar o entendimento de que existe uma importante dimensão política na jurisdição constitucional e que a ADPF é "instrumento idôneo e apto a viabilizar a concretização de políticas públicas”(7). O STF foi cuidadoso ao tomar essa posição, afirmando que cabe ao Judiciário agir quando forem descumpridas as políticas públicas que forem constitucionalmente determinadas. Ou seja, não lhe cabe ordinariamente formular ou implementar políticas públicas, mas lhe cabe agir se e quando o Executivo, por ação ou omissão, comprometer a efetividade dos direitos fundamentais, inclusive os direitos sociais como o direito à saúde. Neste sentido, uma terceira decisão do STF deve ser mencionada, por afirmar que deve prevalecer "o objetivo maior do próprio Estado, ou seja, o de assistência à saúde", de modo que esse direito fundamental "não deve sofrer embaraços impostos por autoridades administrativas"(8).

Especialmente acerca do argumento da falta de recursos, o STF já decidiu que o binômio entre a razoabilidade da pretensão e disponibilidade financeira do Estado jamais pode ser operado em detrimento da dignidade humana:

(...) a cláusula da reserva do possível - ressalvada a ocorrência de justo motivo objetivamente aferível - não pode ser invocada, pelo Estado, com a finalidade de exonerar-se do cumprimento de suas obrigações constitucionais, notadamente quando, dessa conduta

(4) BRASIL. Supremo Tribunal Federal. Agravo Regimental no Recurso Extraordinário n. 271.286-8-RS, cit. (5) Id., loc. cit.

(6) Afinal, há o "poder do cidadão de exigir, do Estado, a implementação de prestações positivas impostas pelo próprio ordenamento constitucional" - Id., loc. cit.

(7) BRASIL. Supremo Tribunal Federal. Arguição de Descumprimento de Preceito Fundamental n. 45 DF. Min. Celso de Mello. Decisão monocrática de 29 de abril de 2004. Disponível em: <http:// www.stf.jus.br/portal/jurisprudencia/listarJurisprudencia.asp?s1=\%28ADPF\$.SCLA.\%20E\%2045.NUME. \%29\&base=baseMonocraticas $>$. Acesso em: $1^{\circ}$ maio 2010.

(8) BRASIL. Supremo Tribunal Federal. Recurso Extraordinário n. 226.835-6-RS. 1ª Turma. Min. Rel. IImar Galvão. Acórdão de 14 de dezembro de 1999. Disponível em: <http://redir.stf.jus.br/paginador/ paginador.jsp?docTP=AC\&doclD=251894>. Acesso em: $1^{\circ}$ maio 2010. 
governamental negativa, puder resultar nulificação ou, até mesmo, aniquilação de direitos constitucionais impregnados de um sentido de essencial fundamentalidade. ${ }^{(9)}$

Essas referências a decisões anteriores do STF e ao caráter fundamental do direito à saúde são importantes para situar a discussão em torno da recente decisão do Supremo, a seguir comentada. É importante ter em vista que, atualmente, o tradicional princípio da supremacia do interesse público deve ser interpretado pelas lentes dos direitos fundamentais, como supremacia dos direitos elementares para a realização do princípio da dignidade humana. Ou seja, hoje, o interesse público que deve preponderar é o da máxima efetividade dos direitos fundamentais.

Neste sentido, a doutrina contemporânea dos direitos humanos e fundamentais propõe que seja prestigiada a racionalidade material dos direitos sociais. Com isso, pretende-se que o direito deixe de atender, preponderantemente, à racionalidade formal do positivismo kelseniano. Ferrajoli, por exemplo, constrói sua teoria do garantismo(10) propondo, explicitamente, a superação do paradigma de um direito formal, ao vincular a existência de direitos ao estabelecimento de garantias. Courtis e Abramovich, por seu turno, sustentam a justicialidade dos direitos sociais e o dever estatal de realização material desses direitos ${ }^{(11)}$.

Neste contexto, o Judiciário se vê ocupado com inúmeras ações judiciais contra o Poder Público pedindo acesso a bens e serviços de saúde. Entre o dever de dizer o direito e o argumento de que políticas públicas são de competência do Executivo, o Supremo ouviu a sociedade, por meio de audiência pública. Em sua recente decisão, o mais elevado Tribunal brasileiro procura dialogar com a sociedade, com o Poder Público e com os pacientes, para delinear as balizas para a atuação dos juízes ao fazer valer o mandamento constitucional de que saúde é dever do Estado, garantido mediante políticas sociais e econômicas.

\section{O JUDICIÁRIO CONQUISTA A SAÚDE?}

Em 17 de março de 2010, o Pleno do Supremo Tribunal Federal decidiu Agravo Regimental interposto pela União contra decisão da Presidência do Tribunal tomada em sede de Suspensão de Tutela Antecipada. Neste caso, a União pediu a suspensão de decisão da Justiça Federal que concedera a

(9) BRASIL. Supremo Tribunal Federal. Arguição de Descumprimento de Preceito Fundamental n. 45 - DF. Min. Celso de Mello. Decisão monocrática de 29 de abril de 2004, cit.

(10) FERRAJOLI, Luigi. Derechos y garantías: la ley del más débil. Madrid: Trotta, 1999.

(11) ABRAMOVICH, Víctor; COURTIS, Christian. Los derechos sociales como derechos exigibles. Madrid: Trotta, 2002. 
uma jovem de Fortaleza, no Estado do Ceará, o direito de receber do Poder Público medicamento(12) de alto custo para tratamento de patologia neurodegenerativa rara chamada Niemann-Pick Tipo C.

A decisão do STF, unânime nos termos do voto do Ministro Relator, rejeitou o recurso da União, mantendo a decisão que concedera o acesso individual ao medicamento de alto custo. Em suma, do voto proferido por Gilmar Mendes podem ser destacadas duas importantes contribuições para o aperfeiçoamento do direito sanitário brasileiro: uma confirmação e uma novidade. Por um lado, confirmou-se o entendimento de que o dever de Estado mencionado no art. 196 da Constituição Federal comporta uma obrigação solidária( ${ }^{(13)}$ entre os entes federativos, em favor inclusive de demandas individuais. Por outro lado, procurou-se estabelecer parâmetros para a solução judicial das demandas sobre acesso à saúde. Cumpre analisar as duas contribuições separadamente.

Antes de seguir, é importante referir que esta não é a primeira vez que, ao enfrentar o tema da judicialização de políticas públicas de saúde, o Ministro Gilmar Mendes analisa com precisão as normas pertinentes ao caso concreto, inclusive a própria política de saúde ${ }^{(14)}$. Esse precedente, comentado em Editorial da Revista de Direito Sanitário, destacou-se por percorrer o caminho — fático e legal — desde a norma constitucional até o texto da política pública. $\mathrm{Na}$ vanguarda da discussão sobre o tema está a percepção de que o profissional do direito contemporâneo deve conhecer minuciosamente a teia normativa do direito sanitário, inclusive a imensidão de normas que estão contidas na franja infralegal dos atos normativos que concretizam as disposições legais e constitucionais do direito à saúde ${ }^{(15)}$.

\section{Saúde: direito público subjetivo e obrigação solidária dos entes federativos}

O voto do Ministro Relator reconhece que o debate em torno do direito à saúde, direito prestacional que é, encerra uma tensão entre o mínimo existencial — preocupação com a dignidade humana - e a reserva do possível - consciência dos custos públicos decorrentes dos direitos. Ao mesmo tempo, o voto retoma a doutrina alemã que considera que a proteção dos direitos

(12) Tratou-se do medicamento Zavesca, cujo princípio ativo é o miglustat, produzido pela empresa Actelion.

(13) Obrigações solidárias são, de acordo com a lei civil brasileira (art. 264 do Código Civil), aquelas em que qualquer um dos devedores (solidariedade passiva) é obrigado a pagar o todo. Mutatis mutandis, também há a solidariedade ativa, quando qualquer um dos credores pode reclamar o todo. No contexto do direito sanitário, se está a discutir a solidariedade passiva entre os entes federativos. (14) Ver: JURISPRUDÊNCIA e ementário: STF, processo STA n. 277-AL (julgamento: $1^{\circ}$ dez. 2008). Revista de Direito Sanitário, São Paulo, v. 10, n. 1, p. 264-276, mar./jul. 2009. 
fundamentais inclui não somente a proibição de excesso - própria para tutelar direitos individuais de liberdade - mas também a proibição de proteção insuficiente - que abre espaço para a tutela individual do direito subjetivo público de acesso à saúde.

Ocorre que a proteção suficiente do direito à saúde é definida de pessoa para pessoa conforme o processo saúde-doença individual. Deste modo, é importante que o voto do Relator tenha consignado que, em matéria de direitos sociais, o Estado deve para cada pessoa na medida das suas necessidades. Em outros termos, trata-se do princípio da equidade, que traduz o dever de dar a cada pessoa segundo a sua necessidade. Na lição de Fernando Aith:

No Direito Sanitário, fala-se sobre a aplicação do princípio da igualdade no que se refere, por exemplo, às ações e serviços de medicina preventiva, de vigilância sanitária e epidemiológica. Essas ações e serviços devem ser distribuídos igualmente a todos, sem distinção. No entanto, quando nos referimos à medicina curativa, às ações e serviços de saúde voltados à recuperação da saúde, é preferível nos referirmos ao princípio da equidade: permitir a cada um, em função de sua liberdade, de se beneficiar dos serviços de saúde de que necessita. ${ }^{(16)}$

Essa precisa distinção - e correlação - entre os princípios da igualdade e da equidade indica que o direito à saúde opera tanto na dimensão individual como na dimensão social dos direitos humanos e fundamentais. Essa é a chave para compreender a saúde como um direito público subjetivo. Em outros termos, ele é, a um só tempo, um direito de liberdade e um direito de igualdade. Com relação a isso, Sueli Gandolfi Dallari leciona o seguinte:

a saúde, definida como direito, deve inevitavelmente conter aspectos sociais e individuais (...)

Observado como direito individual, o direito à saúde privilegia a liberdade em sua mais ampla acepção (...)

Examinado, por outro lado, em seus aspectos sociais, o direito à saúde privilegia a igualdade (...)

O direito à saúde ao apropriar-se da liberdade e da igualdade caracteriza-se pelo equilíbrio instável desses valores. ${ }^{(17)}$

O voto do Ministro Gilmar Mendes confirma a saúde como direito que se realiza tanto social como individualmente. Ademais, ratifica que a obrigação estatal de prestar serviços de saúde é solidária entre as esferas federativas da União, dos Estados e dos Municípios. Particularmente com

(15) Ver: DALLARI, Sueli Gandolfi. Editorial. Revista de Direito Sanitário, São Paulo, v. 10, n. 1, p. 8-9, mar./jul. 2009.

(16) AITH, Fernando. Curso de direito sanitário: a proteção do direito à saúde no Brasil. São Paulo: Quartier Latin, 2007.

(17) DALLARI, Sueli Gandolfi. O direito à saúde. Revista de saúde pública. São Paulo, v. 22, n. 1, p. 59, fev. 1988. 
relação ao argumento em sentido contrário, o voto ponderou que a descentralização dos serviços no sistema de saúde, com o fim de aumentar a qualidade e de ampliar o acesso, não indica a inexistência de solidariedade, mas, bem ao contrário, confirma que a obrigação dos entes federativos é solidária. Trata-se de importante contribuição jurisprudencial para interpretar o art. 23, inciso II, da Constituição Federal, de acordo com a lógica constitucional de proteção dos direitos fundamentais. Com efeito, de acordo com este dispositivo constitucional, "cuidar da saúde e assistência pública, da proteção e garantia das pessoas portadoras de deficiência" é competência comum da União, dos Estados, do Distrito Federal e dos Municípios.

Esse entendimento já fora manifestado pelo Judiciário, inclusive pelo próprio STF, em decisões anteriores. Igualmente, a literatura especializada em Direito Sanitário já sustentava que o art. 196 constitucional impõe solidariamente - entre a União, os Estados, o Distrito Federal e os Municípios - o dever de garantir a todos o acesso aos produtos e serviços necessários à saúde.

\section{PARÂMETROS PARA SOLUÇÕES JUDICIAIS EM MATÉRIA DE SAÚDE}

Além de confirmar a saúde como direito subjetivo público correlato a um dever estatal que comporta uma obrigação solidária entre os entes federativos, o voto do Ministro Gilmar Mendes assume o papel de baliza para o tratamento pelo STF, e pelo Judiciário em geral, do tema da judicialização da saúde. Com efeito, o voto em comento esmiúça os elementos jurídicos do art. 196 da Constituição Federal.

O primeiro aspecto a ser observado é que o direito à saúde, como a quase totalidade dos direitos, não é absoluto, portanto é razoável estabelecer a premissa de que deve haver limites para a concessão de serviços ou bens pleiteados individualmente em nome do direito à saúde. Dialeticamente, não obstante não seja absoluto, no espaço em que for aplicável, o direito à saúde deve ser realizado em plenitude, o que pressupõe o poder-dever de impor judicialmente o cumprimento da obrigação estatal em matéria de saúde. Neste particular, é importante referir as seguintes palavras da decisão ora analisada:

esse direito subjetivo público é assegurado mediante políticas sociais e econômicas, ou seja, não há um direito absoluto a todo e qualquer procedimento necessário para a proteção, promoção e recuperação da saúde, independentemente da existência de uma política pública que o concretize. Há um direito público subjetivo a políticas públicas que promovam, protejam e recuperem a saúde. 
Deste modo, o que existe, a priori, é o dever estatal de promover políticas públicas que realizem o mandamento constitucional de garantir a todos o acesso aos bens e serviços de saúde necessários para cada situação particular, em todos os níveis de atenção. Trata-se do princípio da integralidade. Ocorre que o Poder Público, ao projetar e concretizar as políticas públicas de saúde, administra recursos orçamentários limitados, realidade que não é desconsiderada pela decisão ora comentada. Em função disso, o voto do Relator estabeleceu outra premissa, a saber:

a garantia judicial da prestação individual de saúde, prima facie, estaria condicionada ao não comprometimento do funcionamento do Sistema Único de Saúde (SUS), o que, por certo, deve ser sempre demonstrado e fundamentado de forma clara e concreta, caso a caso.

Por certo, o Judiciário tem seu papel a cumprir quando se verificar o mau funcionamento - ou mesmo o não funcionamento - do SUS. Do mesmo modo, essa ilegalidade cometida, ainda que por omissão, pelo Poder Público, deve ser demonstrada pela pessoa que litigar individualmente. Não obstante isso, para que não seja esvaziado o sentido do direito à saúde como direito humano fundamental, o Judiciário deve ponderar sempre que estabelecer critérios para a concessão/denegação dos pedidos individuais. Esses critérios não poderão jamais impossibilitar a tutela jurisdicional do direito à saúde. Aliás, o voto de Gilmar Mendes reitera que, na ordem constitucional brasileira, tanto os direitos individuais como os direitos sociais - inclusive o direito à saúde - são igualmente direitos fundamentais com aplicação imediata, por força do $\S 1^{\circ}$ do art. 5을 da Constituição Federal.

O voto ora analisado apresenta um importante diagnóstico do direito sanitário brasileiro, quando afirma que, em boa medida, existem políticas públicas e regras definidas, sendo que o problema está principalmente na implementação dessas políticas. Ou seja, "o problema não é de inexistência, mas de execução (administrativa) das políticas públicas pelos entes federados".

É importante perceber que essa conclusão se dá com base dos debates que ocorreram no Tribunal por ocasião da Audiência Pública sobre Saúde, convocada para fazer ouvir a sociedade, o meio acadêmico e órgãos de Estado e de governo em razão do crescente número de demandas judiciais em torno da tutela individual do direito à saúde. Neste sentido, a judicialização da saúde é, também, um laboratório da democracia brasileira. Se é certo que a democracia que se quer não é apenas a democracia formal do voto periódico e obrigatório, então há que se querer democratizar todos os espaços públicos de decisão, o que inclui democratizar o Poder Judiciário.

Particularmente no que toca ao direito à saúde, é importante recordar que seu reconhecimento pela Constituinte de 1988 foi resultado do processo social do movimento sanitarista dos anos 1970 e 1980. Desde então, a 
democracia sanitária é um princípio ordenador do direito sanitário brasileiro(18). E o debate continua atual, por exemplo, nas discussões fomentadas pela inclusão da saúde no projeto Direito Achado na Rua ${ }^{(19)}$. Portanto, considerando o necessário elemento democrático que deve orientar o debate público em torno da judicialização da saúde, é relevante que a audiência pública promovida pelo Supremo Tribunal Federal tenha repercutido no conteúdo da decisão prolatada.

Esse foi um dos primeiros entendimentos que sobressaiu nos debates ocorridos na Audiência Pública-Saúde: no Brasil, o problema talvez não seja de judicialização ou, em termos mais simples, de interferência do Poder Judiciário na criação e implementação de políticas públicas em matéria de saúde, pois o que ocorre, na quase totalidade dos casos, é apenas a determinação judicial do efetivo cumprimento de políticas públicas já existentes.

A partir desse diagnóstico, o voto de Gilmar Mendes definiu o primeiro elemento a ser considerado pelo julgador diante de um pedido individual de tutela do direito à saúde: verificar se existe política pública que diga respeito à prestação de saúde pleiteada no caso concreto. Na hipótese de que haja a política estatal específica, o Judiciário deve fazê-la cumprir e, neste caso, não há que falar em interferência judicial na esfera administrativa, pois o julgador não estará criando a política, apenas ordenando o seu devido cumprimento.

Por outro lado, na hipótese de não haver in casu política de saúde específica com relação ao pedido judicial individualmente formulado, outros elementos devem ser considerados. Ainda segundo o voto ora analisado, nesta hipótese, três situações são possíveis: vedação legal para o fornecimento do medicamento, decisão do próprio SUS de não fornecê-lo e, enfim, omissão legislativa ou administrativa.

Primeiramente, pode ser o caso de expressa proibição legal para o fornecimento do medicamento pleiteado. Novamente evocando a audiência pública, o voto do Relator refere que "é vedado à Administração Pública fornecer fármaco que não possua registro na ANVISA", segundo o art. 12 da Lei n. 6.360/76. E conclui que, regra geral, "o registro na ANVISA configura-se como condição necessária para atestar a segurança e o benefício do produto, sendo o primeiro requisito para que o Sistema Único de Saúde possa considerar sua incorporação". Não obstante, esse critério pode ser excepcionado, quando a própria legislação abrir exceções à necessidade de registro ${ }^{(20)}$.

(18) Sobre isso, ver: AITH, Fernando. op. cit., p. 71-75.

(19) SOUSA JÚNIOR, José Geraldo de et al. (Orgs.). O direito achado na rua: introdução crítica ao direito à saúde. Brasília: CEAD; UNB, 2008.

(20) É o que ocorre, por exemplo, com a aquisição de medicamentos por meio de organizações internacionais intergovernamentais (art. $8^{\circ}, \S 5^{\circ}$, da Lei n. 9.782/99). 
Em segundo lugar, pode ter havido decisão administrativa de não fornecer a prestação reivindicada. Aqui, terá havido decisão do SUS de não custear, ou não fornecer, o tratamento pretendido, por não estar seguro dos efeitos do mesmo. Neste particular, o voto de Gilmar Mendes faz outra distinção.

Em algumas situações, pode haver o fornecimento pelo SUS de tratamento alternativo, mas que não seja adequado para a concreta situação do paciente. Com relação a isso:

em geral, deverá ser privilegiado o tratamento fornecido pelo SUS em detrimento de opção diversa escolhida pelo paciente, sempre que não for comprovada a ineficácia ou a impropriedade da política de saúde existente.

Essa conclusão não afasta, contudo, a possibilidade de o Poder Judiciário, ou de a própria Administração, decidir que medida diferente da custeada pelo SUS deve ser fornecida a determinada pessoa que, por razões específicas do seu organismo, comprove que o tratamento fornecido não é eficaz no seu caso. Inclusive, como ressaltado pelo próprio Ministro da Saúde na Audiência Pública, há necessidade de revisão periódica dos protocolos existentes e de elaboração de novos protocolos. Assim, não se pode afirmar que os Protocolos Clínicos e Diretrizes Terapêuticas do SUS são inquestionáveis, o que permite sua contestação judicial.

Em outras, pode ser que o SUS não ofereça nenhuma alternativa de tratamento. Então, o voto analisado distingue a situação em que a pessoa pleiteia participar de um tratamento puramente experimental de outra situação, na qual a pessoa pretende acesso a medicamento que já passou pelos testes clínicos, mas que ainda não foi incorporado pela política de medicamentos do SUS. No caso de tratamento experimental durante testes clínicos, o voto do Ministro Gilmar Mendes é enfático ao afirmar que o SUS não pode ser obrigado a custear a participação de pacientes em testes clínicos da indústria farmacêutica, sendo que essa participação se dá de acordo com as regras para a pesquisa médica, havendo o dever de o laboratório de pesquisa continuar fornecendo o medicamento para o paciente mesmo após o término dos testes clínicos. No entanto, no caso de medicamentos novos ainda não incorporados à política pública de acesso a medicamentos:

Parece certo que a inexistência de Protocolo Clínico no SUS não pode significar violação ao princípio da integralidade do sistema, nem justificar a diferença entre as opções acessíveis aos usuários da rede pública e as disponíveis aos usuários da rede privada. Nesses casos, a omissão administrativa no tratamento de determinada patologia poderá ser objeto de impugnação judicial, tanto por ações individuais 
como coletivas. No entanto, é imprescindível que haja instrução processual, com ampla produção de provas, o que poderá configurar-se um obstáculo à concessão de medida cautelar."

Este, talvez, seja um dos aspectos da decisão comentada que tragam maior polêmica. Aqui, o voto sugere, literalmente, que haja maior rigor para a concessão de medidas liminares contra o Poder Público em ações judiciais para acesso a medicamentos. Em realidade, um balanço dos parâmetros de decisão delineados pelo voto de Gilmar Mendes indica uma tendência de restrição das hipóteses de concessão liminar da tutela judicial.

Com efeito, ficou claro que: (1) medicamentos sem registro, a princípio, não devem ser fornecidos pelo SUS; (2) medicamentos em fase de testes clínicos na indústria farmacêutica não podem ser exigidos do Poder Público; e (3) medicamentos novos ainda não incorporados à política pública de acesso a medicamentos podem ser concedidos, mas, a princípio, apenas após dilação probatória. Sobram as situações em que: (1) a política pública é clara com relação às prestações que o Poder Público se comprometeu a dar, sendo que neste caso, sem dúvida, o cumprimento fiel da política de saúde deve ser garantido pelo Judiciário, inclusive liminarmente; (2) a política pública não oferece tratamento requerido, mas oferece tratamento alternativo, quando será dada preferência ao tratamento pelo SUS, exceto se for provado que, para o paciente, em seu caso específico, este tratamento alternativo é inadequado e o tratamento negado é o pertinente.

Por fim, pode ser que se trate de omissão administrativa ou legislativa. No primeiro caso, volta-se à situação referida logo acima, dos medicamentos novos ainda não incorporados aos protocolos terapêuticos do SUS. A última hipótese, de omissão legislativa, não foi enfrentada diretamente nas razões do voto ora analisado. Não obstante isso, é importante refletir sobre as consequências da omissão do legislador, considerando, por um lado, a pouca efetividade do mandado de injunção no direito brasileiro e, por outro, as necessidades concretas de atuação legislativa, como é o caso da regulamentação da Emenda Constitucional n. 29 sobre o financiamento da saúde pública.

De todo modo, lê-se no voto do Relator que o alto custo não é, de per se, motivo para o não fornecimento do medicamento pelo Poder Público. E cabe ao Executivo comprovar que haveria grave lesão à ordem, à economia, à saúde e à segurança públicas na hipótese de concessão da tutela jurisdicional pretendida pelo paciente. Assim, o argumento da falta de recursos financeiros não é suficiente para impedir a tutela individual do direito à saúde. Isso fica muito claro no voto do Ministro Celso de Mello, que textualmente afirma que o interesse financeiro do Estado é secundário e não sobrepõe o interesse maior que é a plena realização dos direitos fundamentais, inclusive o direito à saúde. Ainda segundo o voto de Celso de Mello, a reserva do possível não pode servir como argumento para o Estado violar os direitos 
fundamentais(21). Enfim, em razão do princípio da proteção da dignidade humana, é razoável sustentar que, havendo dúvidas sobre a decisão correta a ser tomada, será o caso de conceder a tutela individualmente pretendida, por aplicação do critério de primazia dos direitos fundamentais.

Outro critério - que, aliás, foi muito bem lembrado pelo Ministro Celso de Mello em seu voto - é o da proibição de retrocesso em matéria de proteção de direitos fundamentais. Este pode ser um poderoso argumento para impedir que se retroceda no acesso a medicamentos no Brasil, na hipótese de rigorosa aplicação dos parâmetros delineados no voto do Ministro Gilmar Mendes e de recrudescimento dos limites para a tutela individual do direito à saúde.

\section{CONSIDERAÇÕES FINAIS}

O voto do Ministro Gilmar Mendes apresenta importante diagnóstico do direito sanitário brasileiro, duas décadas depois do reconhecimento constitucional da saúde como direito fundamental e do início da implantação do SUS: muitas vezes as políticas públicas de saúde existem, mas não são efetivadas. Ademais, a decisão do STF confirma que o direito à saúde implica responsabilidade solidária entre a União, o Estado e o Município. Para o cumprimento dessa obrigação pela via judicial, concretamente, devem ser atendidos, segundo a decisão em comento, certos parâmetros que devem conduzir a decisão judicial. Tais critérios não são de cumprimento obrigatório, ou seja, não vinculam as decisões dos magistrados que, diariamente, em todos os cantos do país, trabalham em processos envolvendo o direito à saúde. Não obstante isso, essas balizas, apresentadas com ponderação no voto do Ministro Relator, significam um passo importante para o aperfeiçoamento do direito sanitário. Sua maior contribuição é refinar a técnica jurídica para a aplicação do mandamento constitucional de que saúde é direito de todos e dever do Estado. Uma vez delimitados tais parâmetros, o grande desafio é aplicá-los. Com sabedoria, o voto de Gilmar Mendes assevera que se trata de um enfrentamento casuístico, sem respostas definidas a priori.

\section{REFERÊNCIAS BIBLIOGRÁFICAS}

ABRAMOVICH, Víctor; COURTIS, Christian. Los derechos sociales como derechos exigibles. Madrid: Trotta, 2002.

AITH, Fernando. Curso de direito sanitário: a proteção do direito à saúde no Brasil. São Paulo: Quartier Latin, 2007.

(21) BRASIL. op. cit. 
BRASIL. Constituição Federal de 1988. Disponível em: <http://www.planalto.gov.br/ ccivil_03/Constituicao/Constitui\%C3\%A7ao.htm>. Acesso em: 1ำ maio 2010.

Supremo Tribunal Federal. Agravo Regimental na Suspensão de Tutela Antecipada n. 175 (Ceará). Acórdão de 17 de março de 2010. Publicado em 30 de abril de 2010. Disponível em: <http://redir.stf.jus.br/paginador/ paginador.jsp?docTP=AC\&docID=610255>. Acesso em: 1ำ maio 2010.

Supremo Tribunal Federal. Agravo Regimental no Recurso Extraordinário n. 271.286-8-RS. 2ª Turma. Min. Rel. Celso de Mello. Acórdão de 12 de setembro de 2000. Disponível em: <http://redir.stf.jus.br/paginador/ paginador.jsp?docTP=AC\&docID=335538>. Acesso em: 1ำ maio 2010.

Supremo Tribunal Federal. Arguição de Descumprimento de Preceito Fundamental n. 45 - DF. Min. Celso de Mello. Decisão monocrática de 29 de abril de 2004. Disponível em: <http://www.stf.jus.br/portal/jurisprudencia/ listarJurisprudencia.asp?s1=\%28ADPF\$.SCLA.\%20E\%2045.NUME.\%29\& base=baseMonocraticas $>$. Acesso em: 1ำ maio 2010.

Supremo Tribunal Federal. Recurso Extraordinário n. 226.835-6-RS. 1a Turma. Min. Rel. Ilmar Galvão. Acórdão de 14 de dezembro de 1999. Disponível em: <http://redir.stf.jus.br/paginador/paginador.jsp?docTP=AC\&docl $\mathrm{D}=251894>$. Acesso em: 1ำ maio 2010.

DALLARI, Sueli Gandolfi. Editorial. Revista de Direito Sanitário, São Paulo, v. 10, n. 1, p. 7-11, mar./jul. 2009.

O direito à saúde. Revista de saúde pública. São Paulo, v. 22, n. 1, p. 57-63, fev. 1988.

; NUNES JÚNIOR, V. S. Direito sanitário. São Paulo: Verbatim, 2010.

FERRAJOLI, Luigi. Derechos y garantías: la ley del más débil. Madrid: Trotta, 1999.

JURISPRUDÊNCIA e ementário: STF, processo STA n. 277-AL (julgamento: 1ำ dez. 2008). Revista de Direito Sanitário, São Paulo, v. 10, n. 1, p. 264-276, mar./jul. 2009.

SOUSA JÚNIOR, José Geraldo de et al. (Orgs.). O direito achado na rua: introdução crítica ao direito à saúde. Brasília: CEAD; UNB, 2008. 